\title{
PHILOSOPHICAL ISSUES OF RECYCLING
}

\section{Vorasun Buranakarn ${ }^{1}$}

\section{Introduction}

This paper aims to examine recycling as a philosophical concept from a scientific point of view. To understand how one can generate new knowledge in the world of science, a philosophical scientific methodology can be used to answer the underlying questions. The underlying questions in this paper are "What is recycling?, what does "scientific" recycling mean?, what is the relationship between nature and recycling?, and how does recycling relate to society?" To answer these questions, literature from different areas of study, such as archaeology, ecology, and science, will be reviewed. The ideas of each area of study will provide a process of thought and also evidence, which can support a recycling concept. Some studies may provide facts and some provide theories related to recycling. The methods developed by Gale (1979) and Kuhn (1996) will be used as a tool to define and answer the underlying philosophical questions of recycling. Gale defined the word "Philosophy" as

\footnotetext{
${ }^{1}$ Ph.D., Lecturer, Department of Architecture, Faculty of Architecture, Chulalongkorn University, Bangkok, Thailand.
}

“ ... that ultimate system of concepts which people refer to in explanations of the events and occurrences of their lives." (Gale 1979:6)

According to Gale (1979), naturalistic and non-naturalistic are two types of philosophical concept. Naturalistic philosophy believes in the natural processes of sensation and perception such as seeing, hearing, touching, etc. Non-naturalistic philosophy is the other basic outlook. It believes in perceptions such as God, spirit, and so forth. In addition to the sensations, three main categories of philosophy are metaphysics, epistemology, and logic. Metaphysics (Aristotle's) has two primary concepts, which are matter (the stuff which something is made of) and form (the pattern or arrangement of the stuff). Epistemology refers to a theory of knowledge. An empirical epistemology is reliant on experience or observation alone without regarding systems and theories. Empiricist epistemology is the theory that all knowledge originates in experience without the aid of science or theory, relying on observation and experience especially in the natural sciences; for instance, medical doctors develop their knowledge by practising. Rationalism emphasizes the 
human mental power of reason rather than the human mental power of empirical sensation (empiricism). Logic is a method or process for answering the philosophical question, whether it is inductive or deductive, true or false, and so on. Two goals of science are 1) prediction and control; 2) explanation and understanding.

New knowledge can be created in several ways. One way to discover knowledge is through perception. The sensory element of perception is a correspondence between the real, metaphysical features of the properties of objects and the epistemological features of the raw qualities of our perceptions. The pattern, or arrangement, of the sensory elements is a sensory quality that corresponds to the time-series pattern as experience before and after.

"Rom Harre' believes that new hypotheses get established when they have been shown to involve new objects or properties which can be fitted into consistent causal pictures of the observational world." (Gale 1979:209)

Recycling might be an observation from nature according to Gale's definition. Kuhn (1996) identifies three classes of problems in scientific research. First is a class of facts that the paradigm has shown to be particularly revealing of the nature of things (experiments). Second, a thought without inherent interest, can be compared directly with predictions from the paradigm theory (theory and observation). Third is the fact from activities of normal science. Most physical scientists assume that the universe is composed of microscopic elements and can be explained in shape, size, motion, and interaction. Metaphysically, the question is what sorts of entities the universe does and does not contain. Methodologically, the question is what ultimate laws and fundamental explanations can describe specific motion and interaction of natural phenomenon. These scientific questions are considered in this paper.

Natural observation seems to be an appropriate approach to answer the underlying questions of recycling based on a scientific point of view. According to Gale (1979), the observation fits into an empirical epistemology which relies on experience and the observations of science. In addition to Kuhn (1996), the observation can be explained as a problem in scientific research. Kuhn (1996) describes that the scientific paradigm can be discovered by an observation experiment of the nature of things. The paradigm based on observation provides scientific thought and theory. The observation of natural recycling can achieve two scientific goals, which are 1) prediction and control; 2) explanation and understanding.

\section{Literature Reviews}

\section{Nature}

To understand the concept of recycling, nature and its system have to be reviewed for background knowledge. What is nature? The word "nature" determines the object in the sense of the existence of things in general. Nature is considered from the material point of view as all objects from human experience (Ellington 1985:39). 
Nature is the existence of things. Laws of nature are the explanation of how the natural system works. One can determine nature as the whole object of all possible experience. Experience from this approach means the rules of observation of nature and the laws of nature. What are the conditions of the possibility of experience from all the universal laws of nature? Not all empirical judgments are judgments of experience. People have tried to understand natural systems by observation and maintain them by experience. Experience teaches us what exists and how it exists. Conversely, experience never teaches us the nature of things in themselves. As a result, people have proceeded to discover more experiences and laws of nature, which are still outside their current experience.

"The understanding does not derive its laws (a priori) from, but prescribes them to, nature." (Ellington 1985:61)

What is a law of nature? How one can discover the laws of nature? The possibility of experience generally is a universal law of nature. The principles of experience are the various laws of nature. One can not conclude that the universal laws of nature are nature by human experience. On the other hand, one should inquire from nature. The laws of nature can proceed from one of two reasons. Firstly, these laws are drawn from nature by experience, or secondly, nature is derived from the laws of the possibility of experience in general; the ordinary universal conformity to law of the latter. With this concept, the scientist firstly considers extended nature, and secondly thinks of nature. Natural science determines the first will treat its object according to a priori principles, and the second, according to laws of experience.

How does a human experience nature? What is the relationship of nature to recycling? In human experience, the existence of things in nature act as a cycle, changing their form and transforming themselves to another state. For instance, water changes its form to vapor. A condensation of vapor converges into a cloud and finally drops as rain back to the earth. As the main component and primary food source of nature, plant photosynthesis is evident in many different species. These plants behave in a similar way to use and to provide nutrients to the environment such as the cycle of discarding old leaves and recycling minerals. The recycling of leaves is aided by fungi and bacteria. Various arrangements of roots and microorganisms at ground level facilitate organic closed-loop mineral cycles.

What is the relationship of life to nature? Immanuel Kant, 1724-1804, observed that the laws of nature are life. Life can exist only under certain physical conditions. Bodies on which these conditions have not been evolved will naturally be uninhabited. Space and time produce a concept of nature, the existence of things. A quality is universal if it is intensity-invariant, and a quality is universal if it belongs to all physical objects within the scope of our observations (Butts 1986:77).

What is a relationship of nature to society? To answer this question, Canver (1991) refers to Frederick Engels. He states the law of the relationship between nature and 
thought, to understand both nature and society, and society as nature. This law explains that everything is relative as positive and negative, part and whole, and simple and compound. This law also emphasizes that life is part of the natural system with all evolution.

"Man lives from nature, i.e., nature is his body, and he must maintain a continuing dialogue with it if he is not to die. To say that man's physical and mental life is linked to nature simply means that nature is linked to itself, for man is part of nature... " (Karl Marx 1975:328-9 quoted by Canver: 1991:226)

"Society has its basis in labor, and labor in the material world mediates people and nature. The worker can create nothing without nature, the external world, and through labor, people become human." (Canver 1991:225-226)

Therefore, people are a part of nature. Society relies on nature as its support system. Man pretends to be external to nature and changes it. In this way he changes his own nature into a built environment.

"Man acts upon external nature and changes it, and in this way he simultaneously changes his own nature." (Karl Marx 1977:283 cited by Canver 1991:116)

This new environment increases the degree of human independence from the support system. Once nature is changed or no longer supports the new environment, it declines.
Nature is not a given and it is subject to development and change according to principles and directions. Moreover, nature changes according to the rules of natural selection and the survival of the fittest. It must be recognized that man is part of nature. If nature changes, it also effects man.

What are other approaches for recycling? Do the other approaches have the same or similar meaning? According to literature, feedback, control, and reproduction have similar definitions to recycling. Sometimes recycling means feedback, control force, reinforcement, reproduction, recreation, and regeneration. In this paper feedback and control, reproduction, and recycling will be reviewed.

\section{Feedback and Control}

What is feedback? How is feedback important? From an ecological point of view, Odum (1975) describes feedback as a control of the ecosystem (natural system). Systems, which survive, build in order to aid the use of energy. Feedback loops are necessary for the survival of systems. All processes have energy feedback. If these energy flows are of high-quality, such as the work of human beings or complex machines, people may not realize how much energy it takes to develop energy flows in work elsewhere in the economy. Feedback means control, recycling, and servicing the system. Systems need feedback to build more structure.

What is control? There are two properties of the social system. First, a densely populated urban-industrial area requires enormous 
energy. It is at least two or three orders of magnitude greater than the energy flow that supports life in nature (solar-powered ecosystems). The second is an incomplete or dependent ecosystem in terms of life support since it produces no food, assimilates very little waste, and recycles only a small portion of its water and other material needs. For control theory, the concept of cybernetics is the science of controls. Control in any system, whether a simple temperature-regulating home-heating system or a complex ecosystem, depends on feedback. Feedback occurs when the output or part of the output is "feedback" as input (Odum 1975:219). Feedback acts as a reinforcement to the system.

What is the relationship of feedback and nature? The simplest thing known about recycling in the ecological environment is that nature has structure. It has parts with stable relations between them. In other words, nature has all parts connected as a web. Everything connects to everything else. The greater the number of connections means the stronger the structure (Barker 1968:9). The essential nature in ecological system is the same whether they are physical, social, biological, or behavioral units. They have feedback from either inside and outside their system. Each unit has a time-space focus. In this approach, feedback from outside seems to be necessary for the system. However, all natural systems are open systems since they receive energy from sunlight. The system needs feedback as well as the maintenance of input to generate more structure.

\section{Production and Reproduction}

What is production? Production means the production of use values, goods, and services, and not human beings, unless the context indicates that it is a being used in a wider sense. The production process continually converts material wealth into capital (Canver 1991:198).

What is reproduction? Karl Marx used the word "reproduction" to refer to the reproduction of whole social systems and their structure. Reproduction, in social scientific terms, means the process by which babies are born; the sense of everything that is necessary to create new members of society. For the whole social system, reproducing means the processes that define and determine them, establishing the foundations for their own continuation. It is the way that material production settles the foundation for reproduction that allows for both continuity and change in society. Social reproduction means the total process by which class relations are reproduced. Human reproduction means the processes by which babies are born and increased to be members of the next generation. Reproduction involves change as well as continuity. The process of production itself lays down the conditions with which it can start again (Canver 1991:199). This continuity is the process of reproduction.

According to the materialistic conception, the determining factor is the production and reproduction of immediate life. There are two characteristics of production. Firstly, the production of the necessities of existence, such as food, clothing and shelter, 
and the tools necessary for the production. The second is that the production of human beings; the propagation of the species (Frederick Engels 1972:71-72 cited by Canver 1991:204).

Reproduction is a making process to build more structure. Karl Marx groups reproduction in six different categories; these are biological reproduction, maintenance of labor, reproduction of labor power, reproduction of capital, reproduction of production, and reproduction of capitalist relations.

\section{Recycling}

What is recycling? Why is recycling important? An economist, Herman E. Daly, applied scientific theory to the economic system (Daly and Townsend 1993). His book refers to A. J. Lotka discussion of a closed-loop system of material cycles powered by the sun. Form an economic point of view considering ecology and scientific theory, recycling is one of the economic processes required to reach a steady state of social economics.

"Of the two variables - size of stocks and durability of stocks - only the second requires further clarification. Durability means more than just how long a particular commodity lasts. It also includes the efficiency with which the after-use "corpses" of a commodity can be recycled as an input to be born again as the same or a different commodity." (Daly and Townsend 1993:30)
This idea focuses on the efficiency of social economics. All commodities are degradable. To use them over and over again is one simple way to keep all commodities usable. Recycling is a process to reuse them until they have less value. This can be one definition of recycling in an economic perspective.

What is recycling applied to human society? How does recycling fit into human systems? The system influences its control by loop circuits by which recycled materials reward and stimulate to the effectiveness of the parts for the system. In human systems, people have arranged a feedback currency that is more complex than the geochemical recycling of natural ecosystems. They have invented money, which is a reward feedback for work. The flow of each person is circulated by interconnecting loops. The economic system provides rewards for each person, and the system designs the parts. Natural systems design themselves by their evolutionary devices. A closed-loop is a principle of survival for a system (Odum 1971:150-151). The networks of people have a similar meaning. To understand the role of closed-loops allows us to apply the principles to the development of systems, which can survive.

The flow of energy in the biosphere has been continually supporting the building of natural order by arranging patterns from disordered raw materials. The disordered materials are put together into new orders. Disordered materials are reformed from recycling waste products of things that have depreciated after use. Recycling of materials is a typical procedure of material systems 
(Odum 1976:39). Recycling is also a part of human systems, especially when they do not have outside or imported sources of energy concentrations and reserve energy.

Materials and their waste flow around the system. Waste from one part of the system can be returned to be used in another system. For a system to be sustained, most products need to be recycled and used by some part of the system.

How does recycling relate to human society? How can recycling be applied to human society? Urban development systems need the recycling of nutrients from the city back to the agricultural land. In this way farms and cities are in a closed loop cycle and nutrients are recycled to maintain the productivity of agricultural lands (Odum 1988:58). A good system, ecosystem or an economy, uses all by-products to improve its efficiency. Whenever there is a by-product in an ecosystem, the diversity of organisms usually uses and benefits from the products, which become important parts of that system. Similarly, an economy that does not use by-products for useful purposes is less efficient and not an example of good economic practice. For instance, waste is put in landfills, which is poor practice. Reusing materials, such as glass, plastic, wood, and metals, saves the cost of replacing the items, the cost of waste reprocessing, and the cost of storage. By-products should be returned to the environmental cycle in a beneficial form to the nature.

For ecological engineering, the role of recycling of minerals is important. However, it does not include a design for recycling. It acknowledges the importance of the selforganization of species to maximize efficiency and structure throughout recycling, food web development, hierarchical relationships, and population control. Recycling is more implicit than its application in human society (Hall 1995:120).

What is the difference between re-use and recycling? Re-use processes occur after some period of use when an object undergoes a change in the user (a person or social unit) or the activity of use (Schiffer 1977:17). Secondary use occurs when an unmodified item is employed in a different activity. Recycling occurs when a used item is re-manufactured into a new item (Darney and Franklin 1972:3). Recycling and secondary use may or may not involve a change in the user. Lateral cycling occurs when an object is transferred, without change in form or use, from one user to another. A re-use mechanism is an activity that transfers objects from person to person, consequently facilitating recycling, secondary use, lateral cycling and conservatory processes (Schiffer 1977:32).

Re-use is defined as "a change in the user or use or form of an artifact, following its initial use" (Skibo et al. 1995:126). Re-use commonly be viewed as a formation process. Re-use behavior is directly associated with how people use and conserve material resources. Re-use affects the materials remaining to suggest acquisition. The measurement of product acquisition depends on an evaluation of reuse behavior. 
What is the relationship between recycling and humans or animals? Man, one kind of animal in nature, has developed and created independent environments but unlike animals relies on the standard of needs (not wants) in available resources supported by nature. Animals usually adapt themselves to their environments and use nature along with its cycles to support their lives. Animals act as a part of nature to survive and maintain the continuity of their species. If one thinks about the basic needs of human life for survival, physically human bodies need food, water, cloth, and shelter to protect themselves from unsuitable condition and provide comfort. Our human bodies consume both recyclable and nonrecyclable materials. On the other hand, human bodies actually need to consume only recyclable materials such as food, water, cloth, and shelter for protection from natural events. Nature will adjust itself to a new balance whenever elements or physical condition(s) have changed.

"Man lives from nature, i.e., nature is his body, and he must maintain a continuing dialogue with it if he is not to die. To say that man's physical and mental life is linked to natures supply means that nature is linked to itself, for man is part of nature .... Animals produce only according to the standards and needs of the species to which they belong, while man is capable of producing according to the standards of every species and of applying to each object its inherent standard: ... It is therefore in his fashioning of the objective that man really proves himself to be a species-being. Such production is his active species-life." (Karl Marx 1975:328-9 quoted by Canver
1991:226)

\section{Discussion and Conclusion}

In this paragraph all definitions associated with recycling are summarized. Nature is defined as physical things (Ellington, 1985). Laws of nature or networks of people are a process of the interaction of things (Odum, 1971). Laws of nature mean life as processes or connections of things (Butts 1986; Barker 1968). Animals have been produced according to standard needs from nature's capability. Man is part of nature. People interact with nature. Feedback is necessary for a self-generating system. The closed-loop is a principle of survival for a system. Reproduction, in a sense of feedback, means that the structure produces its product again to create more product or build more structure (Karl Marx 1977 from Engels, 1972; Canver, 1991). What is recycling? Recycling means using commodities over and over until they have less economic value to serve human economic growth (Daly and Townsend 1993). Recycling of materials is a typical procedure of material system (Odum, 1976). Nature has recycling to complete the loop. Recycling is an activity to reproduce or use wastes or unwanted product (materials or energy) from the system. Recycling is a pattern to maximize efficiency of the system (Hall, 1995). Re-use is the first step of the recycling process, which means using the results of activity of another system (Schiffer, 1972, 1977; Skibo et al., 1995). Therefore, recycling is part of life and nature. 
The philosophical study of recycling is based on naturalistic beliefs. Natural processes are observed with human perception. As defined by Gale (1979), perception is a pattern that fits into pictures of the observed world. Nature is viewed as existing objects viewed from human experience. Nature can be defined as the matter of metaphysics, which means something is made, and the form of metaphysics which is a pattern or arrangements of things. As metaphysics matter, nature is defined as physical things. As metaphysics form, Laws of nature or networks of human are a process of interaction between things. Laws of nature mean life as viewed by time-scale. Natural structures process and also connect things. Recycling is one law of nature. Based on an understanding, things in natural structures interact and flow through the system as a cycle. Recycling is a major structure of natural cycles. What does scientific recycling mean? Humans experience recycling with their observation of laws of nature or natural structures. New recycling hypotheses can be established from observation. Explanation and understanding, the goals of science, can be applied to answer questions in recycling research. Is recycling necessary for the system? From a scientific point of view, recycling is a feedback pathway to reinforce or reproduce the system. The feedback pathway has been observed and explained from natural cycles. Based upon our experience, recycling is understood as a necessary path for the survival of a system. Recycling is a feedback path to the system, reinforcing flow in a closed-loop, and a reproduction activity to create structure in the system.
What are the tools of scientific recycling? Besides explanation and understanding from Gale (1979), theory and observation may be another way to answer recycling questions.

\section{Why Should Recycling Be Applied to Human Society?}

As stated above, people are a part of nature. Human society and the built environment need support from nature. Recycling is an important cycle of the structure of nature. On a smaller scale, an ecosystem also follows a natural structure. It is a closedloop with recycling organic matter and nutrients. Scientific technology and social development have forgotten to follow this law of nature, recycling.

"Much of our thinking about energy is wrong because feedbacks of goods and services have not been considered on a comparable basis." (Odum 1976:79)

Since man has realized that he is a part of nature, he has begun to observe recycling patterns and apply them to his society. This has not only stabilized his society but also kept it going.

"One of the characteristics of a moderateenergy steady-state economy is more reuse and recycling of all materials." (Odum 1976: 247)

The application of recycling in human society has been proven in China for thousands of years. Taoism is an ancient philosophy-religion that has influenced Chinese thought. The basic principle is that nature, not mankind, is the center of its 
education. The Chinese have applied nature and art in harmony as a whole. The Chinese development has been stable for thousands of years. The criterion of human life pattern is that for everything people take from the earth something has to be returned. The Chinese have been maximizing production with the application of recycling and natural subsidies (Hall 1995:111). The most important principle is that systems and parts of systems interact with and effect one another. Every material component of the ecosystem is used and re-used. Waste from the system is returned to another to be reused as part of its necessary process. For example, waste from animals is returned to the water to be used as nutrients by the plants. Waste from pig farms is used to produce methane, and pond sediment is used to fertilize plantations. Hierarchy is found in all systems, with the top of the hierarchy controlling the next unit below it (Hall 1995:349). A characteristic of all enduring systems is their capacity to recycle.

In nature, productions, including byproducts and waste, from one system are the input of another system, like a food chain in an ecosystem. As a metaphysical concept, scientists have been told what sorts of entities the universe does and does not contain. Methodologically, scientists know what the ultimate laws and fundamental explanations are. Scientists have to consider the order of nature to understand the precision and scope of the world.

Human society is a part of nature. Society requires natural support as outside feedback for its development and continuation. At this point recycling is an important activity for human society since we create our own built environment separately from the natural environment. Society needs to follow the natural cycle and adapt its pattern. If people still ignore recycling or feedback to nature, the natural cycle may change.

All natural materials have their cycles including recycling in the system. Human society has to develop the quality of built materials or man made materials to be recycled. They should correspond to natural behavior. From this point recycling is necessary for human society and needed for scientific research to increase efficiency.

The underlying questions, stated at the beginning of this paper, are "What is recycling?, what does "scientific" recycling mean?, what is the relationship of nature and recycling?, and how does recycling relate to society?"

\section{What Is Recycling?}

Recycling means one way of organizing existing materials (nature) into natural pattern. The natural pattern can be defined as series of the existing materials flowing around the system. At every stage, existing materials have to be used to support the system. Within the natural pattern, materials will move back to the previous stage and keep continuing as a loop of cycle. However, materials in one loop can be moved to another loop. Within the new loop, materials will act, move, and follow the new pattern. 


\section{What Does "Scientific" Recycling Mean?}

According to Gale, two scientific goals are prediction and control; and explanation and understanding. Recycling is one path way of natural pattern. Scientists can explain recycling by observing the nature, the existing materials. Recycling can be explained as a feedback or control to the system. Recycling is necessary to support the system, which continues to produce more products such as nutrients in soil support plants to grow and produce seeds. Recycling is an important factor for scientists to predict and control some parts of nature. Whenever the system has no recycling pathway, it will decline or change to another pattern, which has the appropriate supporting cycle.

\section{What Is the Relationship between Nature and Recycling?}

Nature means a human experience of the existing materials. Nature as a human experience can be predicted based on observation experience. Recycling is a part of observation experience. Nature, the existing materials, acts as a cycle pattern. Recycling, one part of the natural cycle patterns, describes the path way which goes back to the original stage of the observation pattern.

\section{How Does Recycling Relate to Society?}

Since humans are a part of nature, the existing material, humans should maintain a continuing pattern and recycle within the nature. If the system does not maintain a continuing pattern such as reproduction and complete cycle, it will decline. As a part of nature, human society needs to follow natural pattern to survive. From literature, human society has ignored the recycling path way of all activities. Today recycling is considered as an important issue for the society to be sustained. Not only recycling path way is important but also all stages of natural pattern are necessity for human society.

\section{References}

Alfred, E. and Maria G. Miller. 1994. Kant's Theory of Natural Science. New York: Kluwer Academic Publishers.

Barker, Roger G. 1968. Ecological Psychology: Concepts and Methods for Studying the Environment of Human Behavior. Stanford: Stanford University Press.

Brown, M. T. and H. T. Odum. 1981. A Basic Science of The System of Humanity and Nature. Center for Wetlands, University of Florida.

Buranakarn, Vorasun. 1998. Evaluation of Recycling and Reuse of Building Materials Using The Energy Analysis Method. Ph.D. Dissertation, University of Florida.

Butts, Robert E. 1986. Kant's Philosophy of Physical Science. Dordrecht, Holland: D. Reidel Publishing Company.

Canver, Terrell. 1991. The Cambridge Companion to MARX. Cambridge: Cambridge University Press.

Crowe, Norman. 1995. Nature and The Idea of A Man-made World. Cambridge, Mass.: The MIT Press.

Daly, Herman E. and Kenneth N. Townsend. 1993. Valuing the Earth: Economics, 
Ecology, Ethics. Cambridge, Mass: The MIT Press.

Darney, Arsen, and William E. Franklin. 1972. Salvage Markets for Materials in Solid Wastes. Washington, D.C.: US

Environmental Protection Agency.

Durant, Will. 1926. The Story of Philosophy: The Lives and Opinions of the Greater Philosophers. New York: Simon and Schuster, Inc.

Ellington, James W. 1985. Philosophy of Material Nature: The Complete Texts of PROLEGOMENA to Any Future

Metaphysics That Will Be Able To Come Forward As Science. Indianapolis: Hackett Publishing Company, Inc.

Freudenthal, Gad. 1995. Aristotle's Theory of Material Substance: Heat and Pneuma, Form and Soul. London: Oxford University Press.

Gale, George. 1979. Theory of Science: An Introduction to the History, Logic, and Philosophy of Science. New York: McGrawHill, Inc.

Gould, Richard A. and Michael B. Schiffer. 1981. Modern Material Culture: The Archaeology of Us. New York: Academic Press.

Hall, Charles A. S. 1995. Maximum Power: The Ideas and Applications of H. T. Odum. Boulder: University Press of Colorado.

Kuhn, Thomas S. 1996. The Structure of Scientific Revolutions. Third edition. Chicago: The University of Chicago Press.

Miller, Daniel. 1987. Material Culture and Mass Consumption. Oxford: Basil Blackwell Ltd.

Odum, Howard T. 1971. Environment, Power, and Society. New York: John Wiley \& Sons, Inc.

Odum, Eugene P. 1975. Ecology: The Link Between the Natural and the Social Sciences. New York: Holt, Rinehart and Winston.

Odum, Howard T. and Elisabeth C. Odum. 1976. Energy Basis for Man and Nature. New York: McGraw-Hill book company.

Odum, H. T. 1988. Energy, Environment and
Public Policy: A Guide to The Analysis of Systems. UNEP Regional Seas Reports and Studies No. 95, United Nations Environment Programme (UNEP).

Odum, H. T. 1994. Ecological and General Systems: An Introduction to Systems Ecology. Boulder: University Press of Colorado.

Odum, Howard T. 1996. Environmental Accounting: Energy and Environmental Decision Making. New York: John Wiley \& Sons, Inc.

Seamon, David. 1993. Dwelling, Seeing, and Designing: Toward A Phenomenological Ecology. Albany: State University of New York Press.

Schiffer, Michael B. 1972. Archaeological Context and Systemic Context. American Antiquity.

Schiffer, Michael B. 1977. Toward A Unified Science of The Culture Past. In research Strategies I Historical Archaeology. New York: Academic Press.

Skibo, James M., William H. Walker, and Axel E. Nielsen. 1995. Expanding Archaeology. Salt Lake City: The University of Utah Press. 